\title{
Evaluation of roadway Gaussian plume models with large-scale measurement campaigns
}

\author{
R. Briant ${ }^{1}$, C. Seigneur ${ }^{1}$, M. Gadrat ${ }^{2}$, and C. Bugajny ${ }^{2}$ \\ ${ }^{1}$ CEREA, Joint Research Laboratory École des Ponts ParisTech/EDF R\&D, Université Paris-Est, 6-8 avenue Blaise Pascal, \\ Cité Descartes, Champs-sur-Marne, 77455 Marne-la-Vallée Cedex 2 , France \\ ${ }^{2}$ CETE Nord-Picardie, Equipment Technical Study Center for the Nord-Picardie region in France, 42 bis rue Marais Sequedin \\ - BP 10099, 59482 Haubourdin Cedex, France
}

Correspondence to: R. Briant (briantr@cerea.enpc.fr)

Received: 18 September 2012 - Published in Geosci. Model Dev. Discuss.: 25 October 2012

Revised: 7 March 2013 - Accepted: 13 March 2013 - Published: 3 April 2013

\begin{abstract}
Gaussian models are commonly used to simulate atmospheric pollutant dispersion near sources because they provide an efficient compromise between reasonable accuracy and manageable computational time. The Gaussian dispersion formula provides an exact solution to the atmospheric diffusion equation for the dispersion of a pollutant emitted from a point source. However, the Gaussian dispersion formula for a line source, which is convenient to model emissions from on-road traffic, is exact only when the wind is perpendicular to the line source. A novel approach that reduces the error in the line source formula when the wind direction is not perpendicular to the road was recently developed. This model is used to simulate $\mathrm{NO}_{\mathrm{x}}$ concentrations in a large case study (1371 road sections representing about $831 \mathrm{~km}$ ). $\mathrm{NO}_{2}, \mathrm{NO}$ and $\mathrm{O}_{3}$ concentrations are then computed using the photostationary-state approximation. $\mathrm{NO}_{2}$ concentrations are compared with measurements made at 242 locations in the domain area. Model performance is satisfactory with mean normalised errors of $22 \%$ (winter month) to $31 \%$ (summer month). Results obtained here are also compared with those obtained with a previous formulation and with a standard model used for regulatory applications, ADMS-Urban. Discrepancies among the results obtained with those models are discussed.
\end{abstract}

\section{Introduction}

Air quality modelling of the impacts of on-road mobile sources has been conducted using a variety of modelling techniques. Gaussian dispersion models are efficient to model the local impacts of road traffic emissions because they provide a good compromise between reasonable accuracy and manageable computational time. They have been used for instance to assess the effect of emission control measures on future air quality, to assess population exposure to air pollutant concentrations above air quality standards or to help select among various options for a new road location. Given usual Gaussian model assumptions, stationarity and homogeneity (Csanady, 1973), the integration of the point source formula over a finite line is exact only for cases where the wind is perpendicular to the line source. This particularity is used in the US CALINE series of models (Benson, 1992) and in the European Atmospheric Dispersion Modelling System (ADMS-Urban) (McHugh et al., 2001), in which each line source is divided into elementary line sources that are assumed to be perpendicular to the wind direction. An alternative approach (i.e., non-perpendicular) has been to extend the finite line source formulation to other wind directions by derivation of the solution of an infinite line source (e.g., Calder, 1973; Esplin, 1995; Venkatram and Horst, 2006; Briant et al., 2011). The model of Briant et al. (2011) is an extension of the Horst-Venkatram (HV) formulation, that further minimises the error due to the Gaussian formulation for a line source without significantly increasing the computational requirements (it is referred to hereafter as the Polyphemus line source model). In particular, it uses a numerical solution for cases where the wind becomes parallel to the line source, which prevents the solution from diverging. Although this model performs well for 
theoretical cases, it has not been evaluated yet with ambient concentration measurements. Here, we present a comprehensive model performance evaluation with a large case study in France. First, we briefly present this model and we combine it with a Romberg integration, which is an extension of the trapezoidal rule (William et al., 2007), to take into account the road section width (Sect. 2); we also describe briefly the two other models that are included in this model performance evaluation: the HV model and ADMS-Urban. In Sect. 3, we present the results of comparisons between model simulations and nitrogen dioxide $\left(\mathrm{NO}_{2}\right)$ concentration measurements with passive diffusion tubes (Plaisance et al., 2004) conducted by the CETE Nord-Picardie in a large case study. This large case study included 1371 road sections for a total length of about $831 \mathrm{~km}$. The models simulated $\mathrm{NO}_{\mathrm{x}}$ concentrations. $\mathrm{NO}_{2}, \mathrm{NO}$ and $\mathrm{O}_{3}$ concentrations were then computed using the photostationary-state approximation along with the $\mathrm{NO}_{2} / \mathrm{NO}_{\mathrm{x}}$ emission fraction and background concentrations of $\mathrm{NO}_{2}, \mathrm{NO}$ and $\mathrm{O}_{3}$. Measurements were available at 242 locations of the domain area (Paris region). We also confronted the Polyphemus line source model on this case study to the HV formulation (with a special focus on cases where the wind is parallel to the roadway) and ADMS-Urban.

\section{Description of Gaussian plume models}

\subsection{Line source formulation}

The Gaussian formulation of the concentration field for a pollutant emitted from a line source is the result of the integration of the point source solution over the line source (reflection terms are taken into account in the models, but neglected here for simplicity):

$\mathrm{C}(x, y, z)=\int_{y_{1}}^{y_{2}} \frac{\mathrm{Q}}{2 \pi \mathrm{u} \sigma_{y}(s) \sigma_{z}(s)} \exp \left(\frac{-z^{2}}{2 \sigma_{z}^{2}(s)}-\frac{(y-s)^{2}}{2 \sigma_{y}^{2}(s)}\right) d s$

where $\mathrm{C}$ is the pollutant concentration in $\mathrm{g} \mathrm{m}^{-3}$ at location $(x, y, z), x$ is the distance from the source along the wind direction in $\mathrm{m}, y$ and $z$ are the horizontal and vertical crosswind distances, respectively, from the plume centerline in $\mathrm{m}$, $\mathrm{u}$ is the wind velocity in $\mathrm{m} \mathrm{s}^{-1}, \mathrm{Q}$ is the emission rate in $\mathrm{g} \mathrm{s}^{-1}, y_{1}$ and $y_{2}$ the ordinates of the source extremities, and $\sigma_{y}$ and $\sigma_{z}$ are the standard deviations representing pollutant dispersion in the cross-wind directions in $\mathrm{m}$, which are derived from experimental datasets. For wind directions other than perpendicular to the line source, the dependency of standard deviations on the integration variable makes the integration impossible without approximations. Various approximations can be made (Yamartino, 2008); we present here first the formulation recently proposed by Venkatram and Horst
(2006). Next, we describe the modifications made to the HV model, i.e., the Polyphemus line source model. Finally, we briefly describe the formulation of a standard model, ADMSUrban, which is widely used in Europe for regulatory applications and included in this model performance evaluation.

\subsection{The Horst-Venkatram formulation}

The HV model consists in evaluating the integral by approximating the integrand and to excluding from the computation the part of the line source that is downwind of a given receptor. The effective distance $\mathrm{d}_{\text {eff }}$ (Eq. 2) is used to compute $\sigma_{z}$ and a distance $\mathrm{d}_{\mathrm{i}}$ (Eq. 3) from each extremity of the line source section in the wind direction for $\sigma_{y}$.

$\mathrm{d}_{\mathrm{eff}}=x / \cos \theta$

$\mathrm{d}_{\mathrm{i}}=\left(x-x_{i}\right) \cos \theta+\left(y-y_{i}\right) \sin \theta$

where $x$ and $y$ are the coordinates of the receptor and $x_{i}$ and $y_{i}$ the coordinates of the source extremity $i$ (with $i=1$ or 2) in the source coordinate system. The angle $\theta$ represents the angle between the normal to the line source and the wind direction.

Solving Eq. (1) with the HV approximation leads to Eq. (4), which provides the concentration field for all wind directions, except $\theta=90^{\circ}$. The term $u \cos \theta$ represents the projection of the wind velocity onto the normal direction to the source. However, when the wind is parallel to the line source $\left(\theta=90^{\circ}\right)$, the term $\cos \theta$, on the denominator of the equation, makes Eq.(4) diverge. To avoid the singularity of the HV formulation, we simply set here $\theta=89^{\circ}$ instead of $\theta=90^{\circ}$ when the wind is parallel to the road.

$$
\mathrm{C}(x, y, z)=\frac{\mathrm{Q}}{2 \sqrt{2 \pi} \mathrm{u} \cos \theta \sigma_{z}\left(\mathrm{~d}_{\mathrm{eff}}\right)} \exp \left(\frac{-z^{2}}{2 \sigma_{z}^{2}\left(\mathrm{~d}_{\mathrm{eff}}\right)}\right) \times
$$

$\left[\operatorname{erf}\left(\frac{\left(y-y_{1}\right) \cos \theta-x \sin \theta}{\sqrt{2} \sigma_{y}\left(d_{1}\right)}\right)-\operatorname{erf}\left(\frac{\left(y-y_{2}\right) \cos \theta-x \sin \theta}{\sqrt{2} \sigma_{y}\left(d_{2}\right)}\right)\right]$

If $\mathrm{d}_{\mathrm{i}}$, the distance used to compute $\sigma_{y_{i}}$ from both extremities, is negative, the receptor is not downwind of the extremity $i$. A receptor can be downwind of an extremity and upwind of the other. In that case, in the HV formulation, a segment of the source is excluded of the calculation by setting the term: $\operatorname{erf}\left(\frac{\left(y-y_{i}\right) \cos \theta-x \sin \theta}{\sqrt{2} \sigma_{y}\left(d_{i}\right)}\right)$ of Eq. (4) to: $-\operatorname{sign}(\sin \theta)$.

\subsection{The Polyphemus line source model}

Equation (4) has been shown to give satisfactory results (Venkatram and Horst, 2006; Venkatram et al., 2007, 2009), however, the more the wind becomes parallel to the road, the greater the error and it diverges when the wind is parallel to the road. In Briant et al. (2011), this error associated 
with Eq. (4) was computed by comparison to an exact solution (obtained by discretising the line source into a very large number of point sources) and was parameterised using analytical formulas in order to improve the HV formulation:

$\mathrm{C}_{\text {line }}(x, y, z)=\mathrm{C}(x, y, z) \times\left(\frac{1}{\mathrm{~L}\left(x_{\text {wind }}\right)+1}\right)+\mathrm{E}\left(x_{\text {wind }}, y_{\text {wind }}, z\right)$

where $\mathrm{C}_{\text {line }}$ is the corrected concentration, $\mathrm{C}$ is the concentration given by the $\mathrm{HV}$ model (Eq. 4), and $\mathrm{L}$ and $\mathrm{E}$ are correction functions from Briant et al. (2011).

For cases where the wind is parallel to the line source, the use of an analytical / discretised line source combination, allows one to minimise the error induced by the singularity very effectively (Eq. 6). Because this combination is only applied for a small range of wind directions, the increase in the overall computational time is manageable.

$$
\begin{array}{ll}
\text { Concentration }=\mathrm{C}_{\text {line }} & \text { if } \theta \in[0,80] \\
\text { Concentration }=(1-\alpha) \mathrm{C}_{\text {line }}+\alpha \mathrm{C}_{\text {discretized }} & \text { if } \theta \in] 80,90]
\end{array}
$$

This formulation performs well for all ranges of angles and it provides some improvement in terms of accuracy over previous formulations of the line source Gaussian plume model without being too demanding in terms of computational resources.

In addition to what is presented above, the model used here also includes a Romberg integration to account for the road width. This model is implemented in the Polyphemus modelling platform (Mallet et al., 2007), which is open source and distributed under GNU GPL (http://cerea.enpc. fr/polyphemus). For simplicity, we refer hereafter to this Polyphemus line source model as Polyphemus.

\subsection{The Atmospheric Dispersion Modelling System (ADMS-Urban)}

ADMS-Urban is an air quality modelling platform, which includes a line source Gaussian dispersion model that is widely used for regulatory applications in Europe (McHugh et al., 2001). As mentioned above, its approach is based on the fact that when the wind is perpendicular to the line source, Eq. (1) can be solved without any additional approximation:

$$
\begin{aligned}
& \mathrm{C}(x, y, z)=\frac{\mathrm{Q}}{2 \sqrt{2 \pi} \mathrm{u} \sigma_{z}(x)} \exp \left(\frac{-z^{2}}{2 \sigma_{z}^{2}(x)}\right) \\
& \times\left[\operatorname{erf}\left(\frac{y-y_{1}}{\sqrt{2} \sigma_{y}(x)}\right)-\operatorname{erf}\left(\frac{y-y_{2}}{\sqrt{2} \sigma_{y}(x)}\right)\right]
\end{aligned}
$$

With ADMS-Urban, all line sources are decomposed into a maximum of 10 elementary sources that are perpendicular to the wind. The contributions of each of those elementary sources are summed to form the contribution of one finite line source.

\section{Case study}

\subsection{Simulation set-up}

This case study pertains to a very large road network in the Paris region, France. It includes concentration measurements made during winter 2007 and summer 2008. The dataset used for the simulations contains the following:

- The coordinates of 1371 road sections divided into 5425 smaller, but straight, sections representing a total of $831 \mathrm{~km}$ of linear road length.

- The $\mathrm{NO}_{\mathrm{x}}$ emission rates associated to each road section computed with the CopCETE emission model, of the scientific and technical network (RST) of the French Environment Ministry, from traffic modelling results developed by the Department of Transportation for the Île-de-France region (DRE IF). CopCETE uses the European emission methodology COPERT 3: http://www. emisia.com/copert/Copert3.html (COPERT 4 was not yet available when the original study was conducted).

- The $\mathrm{NO}_{2}$ concentrations measured with passive diffusion tubes at 242 receptor points, located a $2 \mathrm{~m}$ height and at distances ranging from $10 \mathrm{~m}$ to $100 \mathrm{~m}$ or more from the roads, averaged over each overall time period of the measurement campaign ( 4 campaigns: $2 \times$ twoweeks in winter and $2 \times$ two-weeks in summer).

- Meteorological data required for a Gaussian model: meteorological variables such as wind velocity, wind direction and cloud coverage were simulated with the Weather Research and Forecasting model (WRF) (Skamarock et al., 2008) over the measurement time periods. Three nested domains were used (located over Europe, France and the Paris region) as used by Kim (2011). The smaller domain has a resolution of $3 \mathrm{~km}$. The WRF options selected for these simulations are given by Kim (2011). Since Gaussian models use a single set of meteorological inputs for a given hour, domain-wide average values, over the smallest domain, of the meteorological variables were used. In the initial simulation, the stability classes were defined according to wind speed and cloudiness. In a subsequent simulation, atmospheric stability was defined according to the Monin-Obukhov length.

- $\mathrm{NO}_{2}$, $\mathrm{NO}$ and $\mathrm{O}_{3}$ background concentrations: those were computed with the chemical-transport model Polair3D of the Polyphemus platform (Roustan et al., 2011) at two specific locations: Cergy-Pontoise, which represents an urban background site, and Mantes-laJolie, which represents a rural background site. Hourly values at these two locations were used to test the sensitivity of the model results to background concentrations. 


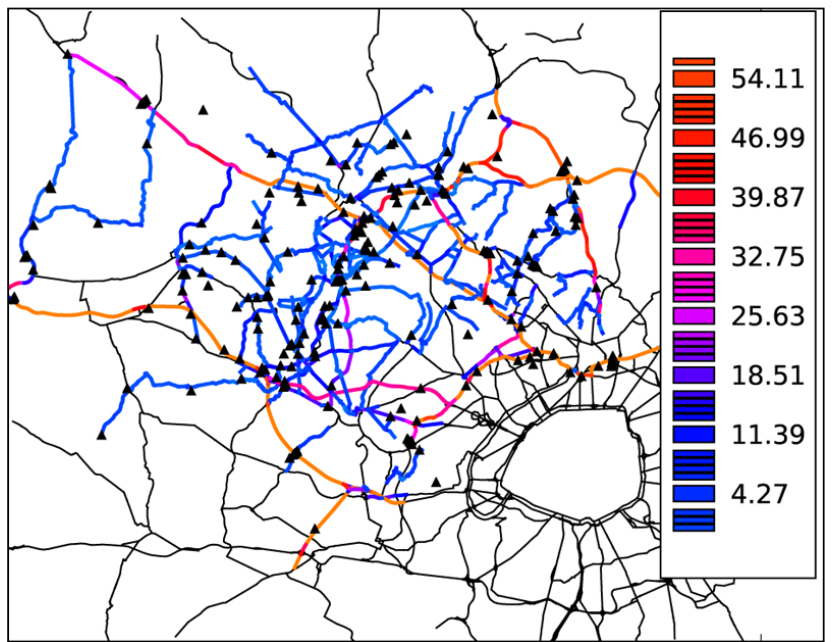

Fig. 1. Road network used for the case study. $\mathrm{NO}_{\mathrm{x}}$ emissions are in $\mathrm{g} \mathrm{day}^{-1} \mathrm{~m}^{-1}$.

We used the same dataset for the HV and Polyphemus model simulations. Background concentrations and emission rates were computed hourly for the year 2005 instead of 2007 and 2008 because of a lack of year-specific traffic modelling data for the roads studied. Also, available emission rates were daily averaged values, which means that variation in traffic (congestion during rush hours for instance) is not taken into account. This traffic averaging induces some uncertainty in the results, which is investigated later using daily traffic profiles.

Figure 1 shows the road network along with $\mathrm{NO}_{\mathrm{x}}$ emissions (in $\mathrm{g} \mathrm{day}^{-1} \mathrm{~m}^{-1}$ ) that were used. Triangles are the locations of passive diffusion tubes and black lines are road that are not included in this case study.

The models presented above only disperse chemically inert compounds $\left(\mathrm{NO}_{\mathrm{x}}\right.$, in this particular case, is assumed to be inert at the local scales considered here). In order to compare simulated values to measured $\mathrm{NO}_{2}$ concentrations, some chemical reactions must be taken into account. The following simple chemical mechanism was implemented:

$\mathrm{O}_{3}+\mathrm{NO} \longrightarrow \mathrm{NO}_{2}+\mathrm{O}_{2}$

$\mathrm{NO}_{2}+\mathrm{h} v \longrightarrow \mathrm{NO}+\mathrm{O}$

$\mathrm{O}+\mathrm{O}_{2} \longrightarrow \mathrm{O}_{3}$

We invoke the photostationary-state approximation for $\mathrm{O}_{3}$, $\mathrm{NO}$ and $\mathrm{NO}_{2}$ to solve the system and compute the $\mathrm{NO}_{2}$ modelled concentrations. We considered a fraction of $10 \%$ of $\mathrm{NO}_{2}$ and $90 \%$ of $\mathrm{NO}$ in the emissions by default. The impact of this assumption is investigated later.

\subsection{General results}

Here, the four-week averaged $\mathrm{NO}_{2}$ concentrations (i.e., averaged value over both two-week time periods) measured by passive diffusion tubes are used for the comparison between measurements and models. Passive diffusion tube measurements have greater uncertainty than continuous measurement methods such as the chemiluminescent technique. This uncertainty may depend on wind velocity and temperature (Plaisance et al., 2004). For example, the tube manufacturer (passam ag) reports an uncertainty of $18 \%$; Plaisance et al. (2004) report an average error of $20 \%$ for passive diffusion tubes compared to chemiluminescence and Soulhac et al. (2012) report a $40 \%$ overestimation of passive diffusion tubes compared to chemiluminescence. During the two measurement campaigns used here, the passive diffusion tube measurements were compared to colocated measurements made at eight fixed stations with the chemiluminescent technique. The passive diffusion tubes tend to overestimate $\mathrm{NO}_{2}$ concentrations with an average error of $17 \%$ in summer (range of $0.4 \%$ to $31 \%$ ) and $12 \%$ in winter (range from $-1 \%$ to $26 \%$ ). These results are consistent with the manufacturer's estimates.

Figure 2 shows the comparison between $\mathrm{NO}_{2}$ measurements and Polyphemus for all measurement sites. On average, modelled values underestimate measurements for both campaigns with a greater underestimation for the winter campaign because measured values are higher in winter than in summer, but modelled values are commensurate in both seasons. The underestimation may be due to the emission rates that do not take into account daily traffic variation or to the meteorological inputs; these issues are addressed below. There is more variability in $\mathrm{NO}_{2}$ concentrations during the summer campaign. Differences between the HV model and Polyphemus are small, therefore, the HV model results are not shown in Fig. 2.

Performance statistics for the two campaigns for this reference case are summarised in Tables 1 and 2. Results are shown using the "rural" dispersion option, which refers to the Pasquill stability classes, in the HV and Polyphemus models, and the Cergy-Pontoise urban background concentrations. Using the Mantes-la-Jolie rural background concentrations led to slightly lower $\mathrm{NO}_{2}$ concentrations (see Supplementary Material); with the Cergy-Pontoise urban background concentrations the model error was similar (mean normalised error) but the model underestimation was slightly larger (mean normalised bias), e.g., $-22 \%$ vs. $8 \%$ for the summer campaign and $-31 \%$ vs. $-23 \%$ for the winter campaign. Using the "urban" dispersion option led to poorer performance for the HV and Polyphemus models (see Supplementary Material) as expected since the road network is located in the Paris suburbs. Differences between both models are not significant (less than $0.1 \mu \mathrm{g} \mathrm{m}^{-3}$ ). These minor differences between the HV model and Polyphemus result from cases where the wind is parallel to the road as documented below. 

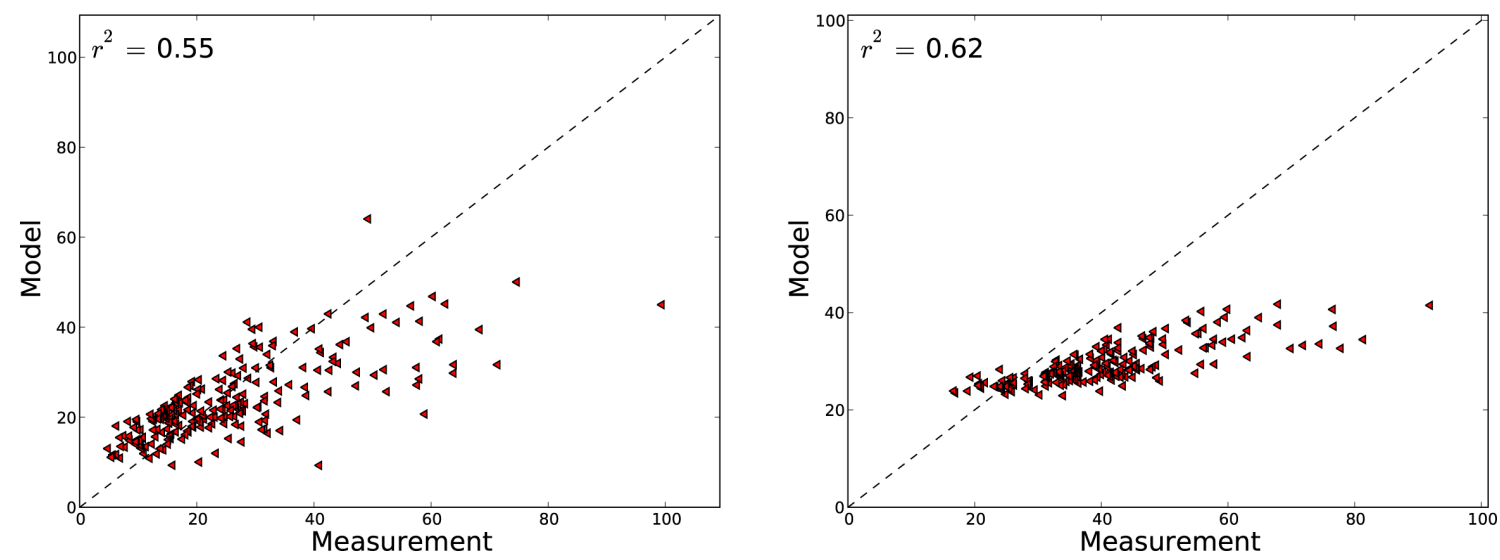

Fig. 2. Scatter plot of measurements versus Polyphemus in $\mu \mathrm{g} \mathrm{m}^{-3}$ (summer campaign on the left and winter campaign on the right).

Table 1. Performance indicators of Polyphemus using the "rural" option for the summer campaign. In the first sensitivity case the GENEMIS temporal profile, a $15 \% \mathrm{NO}_{2}$ fraction and stability classes based on Monin-Obukhov length were used. See Appendix A for the definition of the performance indicators.

\begin{tabular}{|c|c|c|c|}
\hline \multirow{2}{*}{ Performance indicator } & \multicolumn{2}{|c|}{ Reference case } & \multirow{2}{*}{$\begin{array}{c}\text { First sensitivity case } \\
\text { Polyphemus }\end{array}$} \\
\hline & HV & Polyphemus & \\
\hline $\begin{array}{l}\text { Measured monthly mean value } \\
\text { of } \mathrm{NO}_{2}\left(\mu \mathrm{g} \mathrm{m}^{-3}\right)\end{array}$ & \multicolumn{3}{|c|}{26.0} \\
\hline $\begin{array}{l}\text { Modeled monthly mean value } \\
\text { of } \mathrm{NO}_{2}\left(\mu \mathrm{g} \mathrm{m}^{-3}\right)\end{array}$ & 23.5 & 23.6 & 24.4 \\
\hline Correlation & 0.74 & 0.74 & 0.74 \\
\hline $\operatorname{RMSE}\left(\mu \mathrm{g} \mathrm{m}^{-3}\right)$ & 10.9 & 10.8 & 10.4 \\
\hline MNE & 0.32 & 0.32 & 0.31 \\
\hline MNB & 0.08 & 0.08 & 0.07 \\
\hline NME & 0.29 & 0.29 & 0.28 \\
\hline NMB & -0.09 & -0.09 & -0.06 \\
\hline MFE & 0.30 & 0.30 & 0.29 \\
\hline MFB & 0.00 & 0.00 & 0.00 \\
\hline
\end{tabular}

Compared to the mean values, the root-mean-square error (RMSE) is important (around $11 \mu \mathrm{g} \mathrm{m}^{-3}$ for the summer campaign and around $15 \mu \mathrm{g} \mathrm{m}^{-3}$ for the winter campaign). However, the overall correlation is between 0.74 and 0.79 , which indicates that the model explains more than half of the spatial variability observed in the $\mathrm{NO}_{2}$ measurements.

\subsection{Comparison to ADMS-Urban}

Both four-week measurement periods were modelled by the CETE Nord-Picardie with ADMS-Urban for the same case study, but on a smaller domain; 62 out of 242 measurement sites were modelled. Performance statistics are summarised in Table 3 for ADMS-Urban, Polyphemus and the HV model.

All 3 models show good correlations for both campaigns (i.e., greater than 0.7), which suggests good agreement among models. However, ADMS-Urban has a much lower average value than Polyphemus and the HV model for both campaigns. Therefore, ADMS-Urban underesti- mates measurements even more than Polyphemus and the HV model. ADMS-Urban average values are close to the background concentration (i.e., within $1 \mu \mathrm{g} \mathrm{m}^{-3}$ ), which suggests that traffic emissions have a limited impact on the overall concentrations. ADMS-Urban uses the Generic Reaction Set (GRS) chemistry model (Azzi et al., 1993) whereas Polyphemus and HV use the chemistry scheme presented above. However, the effect of the $\mathrm{NO}_{2} / \mathrm{NO}$ chemistry can be excluded as the cause of the difference because the same trend was obtained with $\mathrm{NO}_{\mathrm{x}}$ concentrations.

Other possible reasons are the traffic-induced turbulence, which affects the initial plume depth, the wind speed, which is calculated at the plume centre in ADMS using a logarithmic vertical wind profile (whereas the $2 \mathrm{~m}$ wind speed is used in Polyphemus) and the parameterisation of the dispersion coefficients. Receptors are located at several distances from the roads. Even though a few can be qualified as background sites, most are close to roads and, therefore, dispersion 
Table 2. Performance indicators of Polyphemus using the "rural" option for the winter campaign. In the first sensitivity case, the GENEMIS temporal profile, a $15 \% \mathrm{NO}_{2}$ fraction and stability classes based on Monin-Obukhov length were used. In the second sensitivity case, the same inputs as in the first case along with doubled $\mathrm{NO}_{\mathrm{x}}$ emissions were used. See Appendix A for the definition of the performance indicators.

\begin{tabular}{|c|c|c|c|c|c|c|}
\hline \multirow[t]{2}{*}{ Performance indicator } & \multicolumn{2}{|c|}{ Reference case } & $\begin{array}{l}\text { First } \\
\text { case }\end{array}$ & sensitivity & $\begin{array}{l}\text { Second } \\
\text { case }\end{array}$ & sensitivity \\
\hline & \multicolumn{2}{|l|}{$\mathrm{HV}$} & \multicolumn{3}{|c|}{ Polyphemus } & \\
\hline $\begin{array}{l}\text { Measured monthly mean value } \\
\text { of } \mathrm{NO}_{2}\left(\mu \mathrm{g} \mathrm{m}^{-3}\right)\end{array}$ & \multicolumn{6}{|c|}{40.5} \\
\hline $\begin{array}{l}\text { Modeled monthly mean value } \\
\text { of } \mathrm{NO}_{2}\left(\mu \mathrm{g} \mathrm{m}^{-3}\right)\end{array}$ & 29.2 & 29.3 & & 31.2 & & 36.5 \\
\hline Correlation & 0.78 & 0.79 & & 0.77 & & 0.77 \\
\hline $\operatorname{RMSE}\left(\mu \mathrm{g} \mathrm{m}^{-3}\right)$ & 15.1 & 15.0 & & 13.3 & & 9.4 \\
\hline MNE & 0.26 & 0.26 & & 0.22 & & 0.15 \\
\hline MNB & -0.23 & -0.23 & & -0.18 & & -0.05 \\
\hline NME & 0.29 & 0.29 & & 0.25 & & 0.16 \\
\hline NMB & -0.28 & -0.28 & & -0.23 & & -0.10 \\
\hline MFE & 0.31 & 0.31 & & 0.26 & & 0.16 \\
\hline MFB & -0.28 & -0.28 & & -0.22 & & -0.08 \\
\hline
\end{tabular}

parameters such as initial source height, initial dilution due to traffic-induced turbulence, and the wind speed used in both models are very influential at such short distances from the source. The initial dilution to model the turbulence due to traffic differs between Polyphemus and ADMS; a greater plume vertical dilution implies lower downwind concentrations. A higher initial plume elevation may lead to a delayed plume touchdown and, therefore, lower concentrations at the receptor point. Higher wind speeds due to the application of a vertical wind profile (an option in ADMS) will also lead to lower concentrations (see Eq. 7). Different parameterisations of the dispersion coefficients may also contribute to differences between Polyphemus and ADMS.

Thus, several causes may lead to the underestimation by ADMS, but conducting a thorough investigation of those specific causes is beyond the scope of this work, which focuses on the Polyphemus model.

\subsection{Comparison to the HV formulation}

As expected, the $\mathrm{HV}$ model results are similar to the Polyphemus results because the two models differ significantly only in cases when the wind is close to parallel to the road (Briant et al., 2011). Indeed, because the concentration results are averaged over four-week periods, differences that occur only for a few specific hours when the wind is parallel to the road, have limited influence over the results.

To characterise those situations when the two models may differ, we computed time series for each of the 242 receptor locations and identified situations when the wind is parallel to the road. We computed differences between concentrations obtained with the HV model and with Polyphemus for meteorological situations when the wind is parallel to the road. We selected 3 receptor locations (summer campaign with "rural" option), that are located close to one specific road section each (i.e., receptors influenced by several road sections were not considered). The aim was to enhance the influence of this specific road section on the receptor while avoiding interference from other road sections that may not be parallel to the wind direction. Nevertheless, most receptors showed some similar results. Results are depicted in Fig. 3 for one of these receptors and in the Supplementary Material for the other two.

When the wind is almost parallel to the road, the difference between both formulations is much more important than for other meteorological situations, and the $\mathrm{NO}_{2}$ concentrations are better correlated between both formulations when the wind is not parallel to the road $\left(r^{2}=0.77\right.$ vs. $r^{2}=1$.).

We notice on Fig. 3 that all hours with a large difference between both models occur when the wind is parallel to the road; however, there are also many points with small differences that occur when the wind is parallel to the road. Those points correspond to meteorological situations when the wind is parallel to the road, but from the southeast, i.e., when most of the road is not upwind of the receptor (i.e., the receptor is impacted by a small portion of the road section). Figure 4 (derived from Fig. 3) shows that most of the error between the two models occurs when most of the road is upwind of the receptor. There are still some points with a small difference that occur when most of the source is upwind of the receptor; those can be attributed to situations when the background concentration is predominant (i.e., the model contribution to the total concentration is less significant than the background contribution).

Polyphemus gives higher concentrations than the HV model on average when the wind is nearly parallel to the road. In this particular case where concentrations are underestimated (Fig. 2), this leads to better performance by 
Table 3. Performance indicators of Polyphemus, the HV model and ADMS-Urban for the smaller domain.

\begin{tabular}{|c|c|c|c|}
\hline Summer campaign & HV formulation & Polyphemus & ADMS-Urban \\
\hline $\begin{array}{l}\text { Measured monthly mean value } \\
\text { of } \mathrm{NO}_{2}\left(\mu \mathrm{g} \mathrm{m}^{-3}\right)\end{array}$ & & 22.5 & \\
\hline $\begin{array}{l}\text { Modeled monthly mean value } \\
\text { of } \mathrm{NO}_{2}\left(\mu \mathrm{g} \mathrm{m}^{-3}\right)\end{array}$ & 19.8 & 20.0 & 9.6 \\
\hline Correlation & 0.82 & 0.82 & 0.73 \\
\hline $\operatorname{RMSE}\left(\mu \mathrm{g} \mathrm{m}^{-3}\right)$ & 9.1 & 9.0 & 17.4 \\
\hline MNE & 0.34 & 0.33 & 0.48 \\
\hline MNB & 0.07 & 0.07 & -0.46 \\
\hline NME & 0.29 & 0.29 & 0.58 \\
\hline NMB & -0.12 & -0.11 & -0.57 \\
\hline MFE & 0.32 & 0.31 & 0.68 \\
\hline MFB & -0.10 & -0.01 & -0.66 \\
\hline Winter campaign & HV formulation & Polyphemus & ADMS-Urban \\
\hline $\begin{array}{l}\text { Measured monthly mean value } \\
\text { of } \mathrm{NO}_{2}\left(\mu \mathrm{g} \mathrm{m}^{-3}\right)\end{array}$ & & 35.15 & \\
\hline $\begin{array}{l}\text { Modeled monthly mean value } \\
\text { of } \mathrm{NO}_{2}\left(\mu \mathrm{g} \mathrm{m}^{-3}\right)\end{array}$ & 27.1 & 27.2 & 19.4 \\
\hline Correlation & 0.80 & 0.80 & 0.79 \\
\hline $\operatorname{RMSE}\left(\mu \mathrm{g} \mathrm{m}^{-3}\right)$ & 12.9 & 12.8 & 19.1 \\
\hline MNE & 0.24 & 0.24 & 0.40 \\
\hline MNB & -0.15 & -0.15 & -0.39 \\
\hline NME & 0.28 & 0.28 & 0.45 \\
\hline NMB & -0.23 & -0.23 & -0.45 \\
\hline MFE & 0.28 & 0.28 & 0.52 \\
\hline MFB & -0.20 & -0.20 & -0.52 \\
\hline
\end{tabular}

Polyphemus. However, as previously stated in Sect. 3.2, this underestimation of concentrations might come from the emission rates that do not take into account daily traffic variation and it is not possible to say whether or not concentrations would still be underestimated with better emission rates.

Unfortunately, there are no hourly measurements available to determine which formulation performs better. However, from a theoretical point of view, when the wind is parallel to the road, the HV formulation diverges whereas the Polyphemus formulation uses the analytical/discretised line source combination, so we may conclude that Polyphemus is more accurate for those specific conditions. Here, the $\mathrm{HV}$ model (using a wind direction limit of $89^{\circ}$ to avoid divergence) leads to lower concentrations than Polyphemus, thereby suggesting that divergence would occur for wind direction values closer to $90^{\circ}$ and that the $\mathrm{HV}$ model is sensitive to the choice of this wind direction limit. It would be interesting to conduct a specific study with hourly measurements of a traffic pollutant $\left(\mathrm{NO}_{2}, \mathrm{NO}_{\mathrm{x}}, \mathrm{CO}\right.$, etc.), local meteorological data and well-defined hourly traffic data to confirm this assessment.

\subsection{Computational time}

A major difference between the HV model and Polyphemus is the computational time. As expected, the computational time is greater with Polyphemus because of the corrections made to the HV formulation, mostly for the parallel wind cases. With a $2.67 \mathrm{GHz}$ processor, the computational time required to simulate one meteorological situation for 242 receptors (i.e., the locations of the passive diffusion tubes) and for all 5425 line sources is about $5 \mathrm{~s}$ with the HV formulation, while it is about $50 \mathrm{~s}$ with Polyphemus.

The difference is important and is due to the fact that for each meteorological situation, there are some road sections parallel to the wind, which activate the analytical/discretised line source combination in the Polyphemus formulation. Here, we used a discretisation step set of $1 \mathrm{~m}$ (i.e., 1 point source per metre for each line source) with a maximum set to 1000 point sources per line source so that the computation remained reasonable. Because the total length of all sources is important (about $831 \mathrm{~km}$ ), the increase in computational time is important, a factor 10 , as presented above.

This must be balanced by the fact that the discretisation step for the combination can be adjusted to decrease the computational burden. We chose here to use a $1 \mathrm{~m}$ discretisation step because the overall computational time remained 


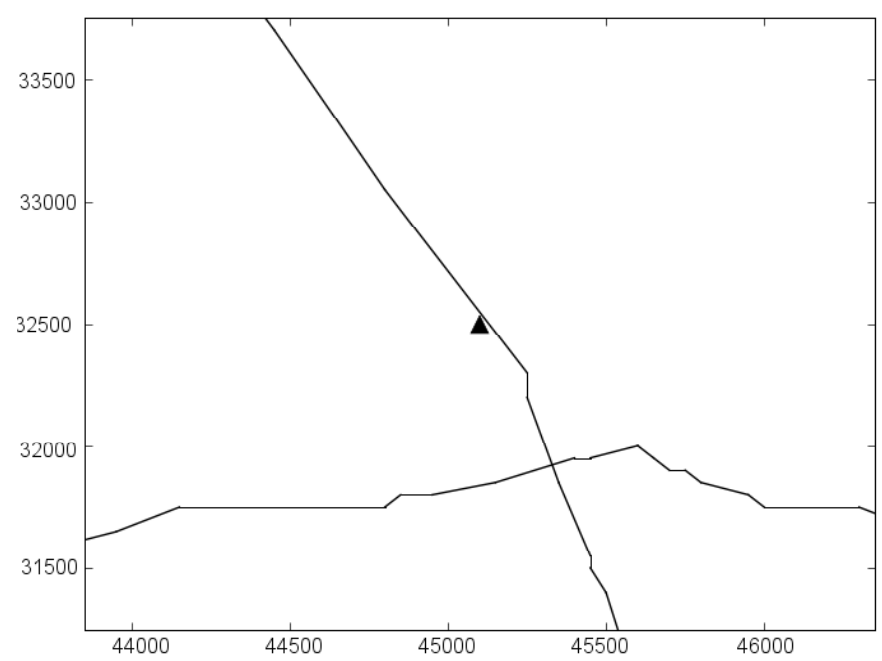

(a)

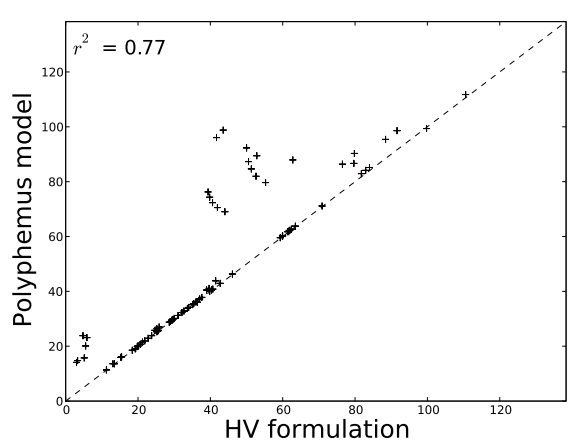

(b)

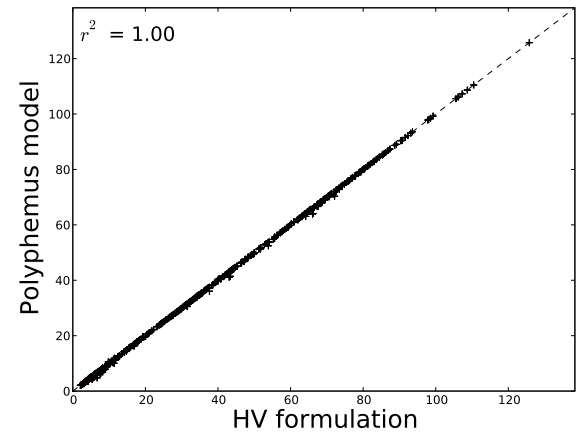

(c)

Fig. 3. Comparison between the $\mathrm{HV}$ and Polyphemus models of simulated $\mathrm{NO}_{2}$ hourly concentrations ( $\mu \mathrm{g} \mathrm{m}^{-3}$, summer campaign). (a): Map of the passive diffusion tube locations with respect to the roads (coordinates are in metres). (b): situations when the wind is parallel to the road $\left( \pm 10^{\circ}\right)$. (c): situations when the wind is not parallel to the road. The road direction is $151^{\circ}\left(0^{\circ}\right.$ represents a wind coming from the north and $90^{\circ}$ a wind coming from the east).

manageable and because it has been shown to lead to an acceptable error (Briant et al., 2011). Note that the above simulation of one meteorological situation, computed with a discretisation step of $5 \mathrm{~m}$ takes about $15 \mathrm{~s}$ instead of $50 \mathrm{~s}$ with a $1 \mathrm{~m}$ step and induces an average difference in concentration of less than $1 \%$ of the average concentration over all receptor points while the difference between Polyphemus and the HV model is still important (see Fig. 5); therefore, a smaller discretisation step would be acceptable to decrease computation burden.

If one wants to simulate a whole month, the overall computational time can be cumbersome for both formulations. However, it can be reduced easily by avoiding to compute duplicate meteorological situations. During the four-week period of simulation, there is a total of $672 \mathrm{~h}(24 \mathrm{~h} \times 7$ days $\times 4$ weeks $)$ while there is a maximum of 216 possible distinct meteorological situations (36 angles, with a resolution of $10^{\circ} \times 6$ stability classes: A, B, C, D, E or
F). It then requires about $3 \mathrm{~h}$ to compute the whole four-week time period with the Polyphemus model. Moreover, because meteorological situations are independent, several processors can be used concurrently to decrease the computational burden further.

Note that two meteorological situations can be considered to be identical if the wind angle and the stability class are identical. The wind velocity does not matter because it is used as a coefficient that is taken into account in postprocessing (see Eq. 4). The computational time of ADMS-Urban is not presented here because it was run on a different computer.

\subsection{Sensitivity to input data}

Even though performance indicators for the reference case seem satisfactory according to Tables 1 and 2, Fig. 2 shows that the models underestimate concentrations, especially during the winter campaign. We are assuming, here, that the error is most likely due to input data rather than model 

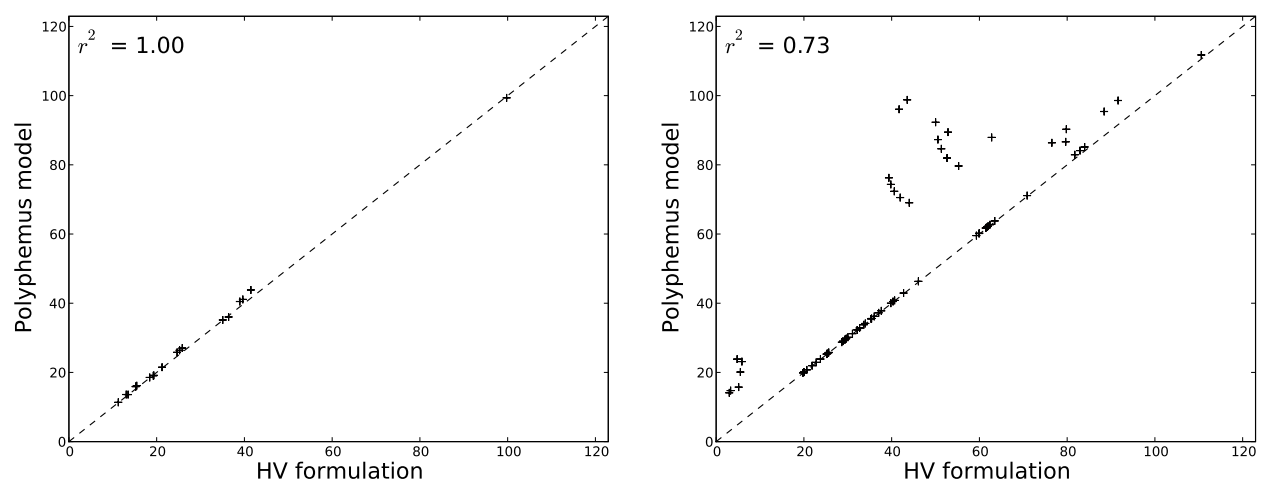

Fig. 4. Comparison between the HV formulation and the Polyphemus formulation (summer campaign). Left side: wind angle equal to $150^{\circ}$ $\left( \pm 10^{\circ}\right)$. Right side: wind angle equal to $330^{\circ}\left( \pm 10^{\circ}\right)$.

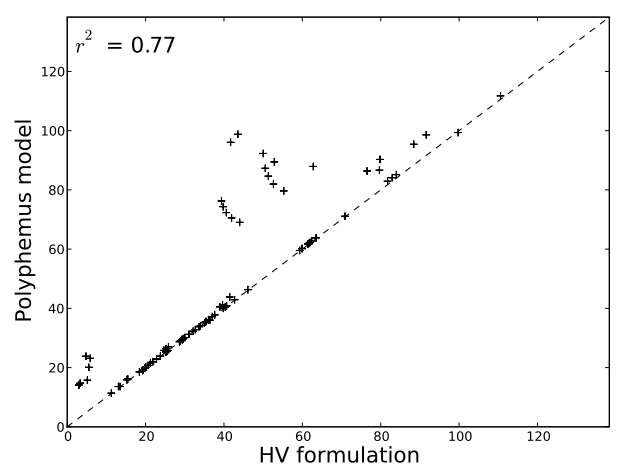

(a)

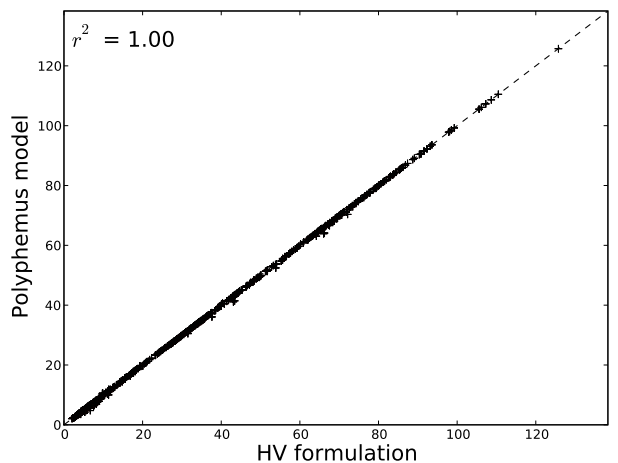

(b)

Fig. 5. Same comparison as in Fig. 3, but with a $5 \mathrm{~m}$ discretisation step for Polyphemus. (a): situations when the wind is parallel to the road $\left( \pm 10^{\circ}\right)$. (b): situations when the wind is not parallel to the road (summer campaign). The road direction is $151^{\circ}\left(0^{\circ}\right.$ represents a wind coming from the north and $90^{\circ}$ a wind coming from the east).

formulation. As mentioned above, emissions are spatially distributed, but constant in time, i.e., they do not take into account daily traffic variation. Furthermore, a $15 \% \mathrm{NO}_{2}$ fraction (instead of $10 \%$ ) would be more representative of traffic conditions in the Paris region in 2007-2008 (Roustan et al., 2011). In addition, the WRF output can be used to provide a more accurate representation of atmospheric conditions using the Monin-Obukhov length to characterise atmospheric stability instead of cloud fraction and wind speed.

Figure 6 and Tables 1 and 2 show simulations results for this first sensitivity case, which uses the GENEMIS (Friedrich and Reis, 2004) road traffic temporal profile, a $15 \% \mathrm{NO}_{2}$ fraction along with a better definition of stability classes using Monin-Obukhov length. The underestimation is still important for the winter campaign even though averaged concentrations have increased by $0.8 \mu \mathrm{g} \mathrm{m}^{-3}$ and $1.9 \mu \mathrm{g} \mathrm{m}^{-3}$ for the summer and the winter campaign, respectively, (averaged concentration of $24.4 \mu \mathrm{g} \mathrm{m}^{-3}$ instead of previously $23.6 \mathrm{\mu g} \mathrm{m}^{-3}$ for the summer campaign and
$31.2 \mu \mathrm{g} \mathrm{m}^{-3}$ instead of previously $29.3 \mu \mathrm{g} \mathrm{m}^{-3}$ for the winter campaign).

In order to evaluate the relative importance of these changes in model inputs, three simulations were run using those three changes (i.e., the GENEMIS temporal profile, a $15 \% \mathrm{NO}_{2}$ fraction and a better definition of stability classes using Monin-Obukhov length) separately instead of combining them as in the first sensitivity case. The use of the Monin-Obukhov length and a $15 \% \mathrm{NO}_{2}$ fraction increase performance for both campaigns while the use of the GENEMIS temporal profile tends to decrease model performance slightly. Nevertheless, the use of a temporal profile for emissions was considered to be relevant despite the decrease in performance, because our purpose was to decrease the overall input data uncertainty rather than to evaluate the effect of individual changes. Therefore, performance indicators for those three cases are shown in Supplementary Material only. 

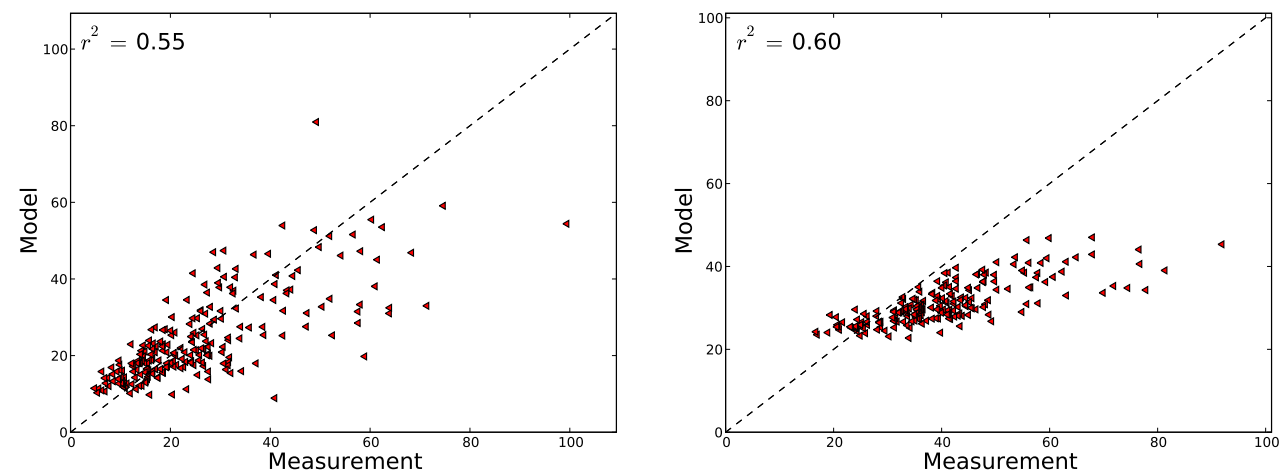

Fig. 6. Scatter plot of measured versus Polyphemus using the "rural" option, the GENEMIS temporal profile, a $15 \% \mathrm{NO}_{2}$ fraction and stability classes based on Monin-Obukhov length (summer campaign on the left and winter campaign on the right).

Figure 6 shows satisfactory results for the summer campaign whereas for the winter campaign a significant model underestimation is visible.

As discussed above, the uncertainty in measurements is important (on average $+17 \%$ in summer and $+12 \%$ in winter). Therefore, the fact that passive diffusion tube measurements tend to overestimate $\mathrm{NO}_{2}$ concentrations could explain why Polyphemus and the HV models underestimate those measurements.

Possible sources of uncertainty include the following. Although all major road sections were modelled, some road sections were not and during winter time, there are additional emissions due to cold start because of the lower temperatures. The influence of cold start has not been shown to increase the total amount of emissions significantly in the Paris region-wide inventory; nevertheless, it is a potential source of underestimation of emissions, albeit not significant for $\mathrm{NO}_{\mathrm{x}}$. In addition, $\mathrm{NO}_{\mathrm{x}}$ and $\mathrm{NO}_{2}$ emissions from certain vehicle classes are underestimated by the use of COPERT 3. For example, $\mathrm{NO}_{\mathrm{x}}$ emissions from diesel cars under urban driving conditions do not appear to have declined substantially up to and including Euro 5, and there is limited evidence to suggest that this same pattern may occur for motorway driving conditions.

Although some Gaussian models allow some corrections for impacts on simple terrain features such as impacts on elevated terrain, most Gaussian models, such as Polyphemus, assume a flat domain. Local effects such as street canyons and noise barriers are neglected with Polyphemus, which may result in model uncertainties. However, the suburban setting of this modelling domain minimises the influence of major features such as street canyons. Furthermore, background concentrations are obtained at a single location, which adds some uncertainty.

We investigate the case where $\mathrm{NO}_{\mathrm{x}}$ emissions could be underestimated due to traffic congestion or greater emissions related to underestimations by the emissions model or a combination thereof. We increased $\mathrm{NO}_{\mathrm{x}}$ emissions by a factor of

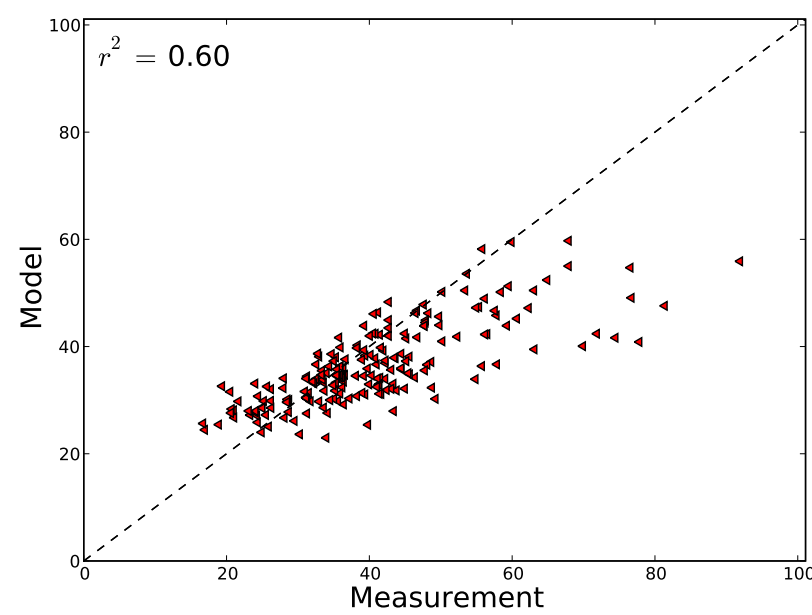

Fig. 7. Scatter plot of measurements versus Polyphemus using corrections as in Fig. 6 with emissions multiplied by 2 (winter campaign only).

two for the winter case. Results are presented in Fig. 7 and Table 2 (second sensitivity case). The model results are in better agreement with the measurements, thereby suggesting a significant underestimation of $\mathrm{NO}_{\mathrm{x}}$ emissions in the winter base inventory that could be due to a misrepresentation of traffic and/or $\mathrm{NO}_{\mathrm{x}}$ emission factors.

According to Chang and Hanna (2004) a "good" model would be expected to have about $50 \%$ of the predictions within a factor of two of the observations, a relative mean bias within $\pm 30 \%$, and a relative scatter of about a factor of two or three (see Appendix A for the definition of these performance indicators). Polyphemus has more than $92 \%$ of its predictions within a factor of two of the observations, a relative mean bias of $10 \%$ and $32 \%$, respectively, for the summer and the winter campaigns, and a relative scatter of less than a factor of 1.2. With the first sensitivity case, these performance criteria are met. Indeed, Polyphemus has more 
than $92 \%$ of its predictions within a factor of two of the observations, a relative mean bias of $6 \%$ for the summer campaign and $26 \%$ for the winter campaign and a relative scatter less than 1.2. Therefore, Polyphemus fulfills the criteria to be considered as a "good" model despite the fact that emission rates were annual averages. In addition, according to Eskridge and Rao (1986), a model is assumed to be "perfect" if its predicted values are within $\pm 30 \%$ of the observed concentrations. Polyphemus modelled values are on average within $\pm 32 \%$ and $\pm 31 \%$ for the summer and the winter campaigns, respectively, in the first sensitivity case.

\section{Conclusions}

The Polyphemus line source model has been presented and evaluated with a case study characteristic of a large roadway system. Uncertainties in input data (emissions, background concentrations, meteorological parameters) and in passive diffusion tube measurements have been discussed. The base simulations reflected operational input datasets and, as such, differed in their levels of detail. As a result, we focused on the uncertainty in traffic emissions and meteorology. According to previous studies, Polyphemus fulfills the criteria to be considered as a "good" model despite the fact that emissions rates were annual averages.

Polyphemus and the HV model, give similar results for the one-month average concentrations; ADMS-Urban tends to lead to lower concentrations. Although no major improvement of Polyphemus with respect to the HV model appears in the one-month averaged results, some major differences can be seen in specific situations when the wind is nearly parallel to the road. Computational time is more important with Polyphemus than with the HV formulation. However, the discretisation step of the analytical/discretised line source combination can be adjusted in Polyphemus to decrease the computational time. Computations can also be paralleled easily to simulate several meteorological situations as needed for most applications. Sensitivity studies showed improvements in model performance when using realistic $\mathrm{NO}_{2} / \mathrm{NO}_{\mathrm{x}}$ emission ratios and the Monin-Obukhov length to define atmospheric stability. The results presented here also suggest the importance of temporally-resolved and spatially-distributed traffic inputs.

\section{Appendix A}

\section{Performance indicators}

$$
\text { - Correlation: } r=\frac{\sum_{i=1}^{N}\left(O_{i}-\bar{O}\right)\left(M_{i}-\bar{M}\right)}{\sqrt{\sum_{i=1}^{N}\left(O_{i}-\bar{O}\right)^{2}} \sqrt{\sum_{i=1}^{N}\left(M_{i}-\bar{M}\right)^{2}}}
$$

- RMSE (root-mean-square error):

$$
\mathrm{RMSE}=\sqrt{\frac{1}{N} \sum_{i=1}^{N}\left(M_{i}-O_{i}\right)^{2}}
$$

- MNE (mean normalised error):

$$
\mathrm{MNE}=\frac{1}{N} \sum_{i=1}^{N}\left|\frac{M_{i}-O_{i}}{O_{i}}\right|
$$

- MNB (mean normalised bias):

$$
\mathrm{MNB}=\frac{1}{N} \sum_{i=1}^{N} \frac{M_{i}-O_{i}}{O_{i}}
$$

- NME (normalised mean error): $\mathrm{NME}=\frac{\sum_{i=1}^{N}\left|M_{i}-O_{i}\right|}{\sum_{i=1}^{N} O_{i}}$

- NMB (normalised mean bias): NMB $=\frac{\sum_{i=1}^{N} M_{i}-O_{i}}{\sum_{i=1}^{N} O_{i}}$

- MFE (mean fractional error): $\mathrm{MFE}=\frac{1}{N} \sum_{i=1}^{N} \frac{\left|M_{i}-O_{i}\right|}{\frac{O_{i}+M_{i}}{2}}$

- MFB (mean fractional bias): $\mathrm{MFB}=\frac{1}{N} \sum_{i=1}^{N} \frac{M_{i}-O_{i}}{\frac{O_{i}+M_{i}}{2}}$

- Fraction of predictions within a factor of two of the observations:

FAC2 = fraction of data that satisfy: $0.5 \leq \frac{M_{i}}{O_{i}} \leq 2$.

- $\mathrm{RMB}$ (relative mean bias): $\mathrm{RMB}=\frac{(\bar{O}-\bar{M})}{0.5(\bar{O}+\bar{M})}$

- RS (relative scatter): $\mathrm{RS}=\exp [\overline{(\ln (O)-\ln (M))}]$

where $M_{i}$ and $O_{i}$ are the modelled and observed values, respectively, and $\bar{x}=\frac{1}{N} \sum_{i=1}^{N} x_{i}$.

\section{Supplementary material related to this article is available online at: http://www.geosci-model-dev.net/6/ 445/2013/gmd-6-445-2013-supplement.pdf.}


Acknowledgements. We acknowledge the GENEMIS project, which provides the emission temporal profile. We also acknowledge the National Centres for Environmental Prediction (NCEP) for providing initial and boundary conditions that were used for the WRF model simulations. Finally, we acknowledge the Department of Transportation for the Île-de-France region (DRE IF) for providing the traffic modelling results.

Edited by: P. Jöckel

\section{References}

Azzi, M. and Johnson, G. M.: Airtrak: new developments, Clean Air, 27, 191-193, 1993.

Benson, P. E.: A review of the development and application of the CALINE3 and 4 models, Atmos. Environ., 26, 379-390, 1992.

Boutahar, J., Lacour, S., Mallet, V., Quélo, D., Roustan, Y., and Sportisse, B.: Development and validation of a fully modular platform for numerical modelling of air pollution, Polair. Int. J. Environ. Pollut., 22, 17-28, 2004.

Briant, R., Korsakissok, I., and Seigneur, C.: An improved line source model for air pollutant dispersion from roadway traffic, Atmos. Environ., 45, 4099-4107, 2011.

Calder, L. K.: On estimating air pollution concentrations from a highway in an oblique wind, Atmos. Environ. 7, 863-868, 1973.

Chang, J. C. and Hanna., S. R.: Air quality model performance evaluation, Meteorol. Atmos. Phys., 87, 167-196, 2004.

Csanady, G. T.: Turbulent Diffusion in the Environment, D. Reidel Publishing Company, Dordrecht, The Netherlands, 1973.

Eskridge, R. E. and Rao, S. T.: Turbulent diffusion behind vehicles: Experimentally determined turbulence mixing parameters, Atmos. Environ., 1967, 20, 5, 851-860, 1986.

Esplin, J. G.: Approximating explicit solution to the general line source problem, Atmos. Environ., 29, 1459-1463, 1995.

Friedrich, R. and Reis, S.: Emissions of air pollutantsmeasurements, calculations and uncertainties, GENEMIS, EUROTRAC-2, Subproject Final Report, Springer Publishers, Berlin, 2004.

Kim, Y.: Modélisation de la qualité de l'air: Évaluation des paramétrisations chimiques et métérologiques, Ph.D. thesis, Université Paris-Est, Marne-la-Vallée, France, http://pastel. archives-ouvertes.fr/pastel-00667777/, 2011 (in French).
Mallet, V., Quélo, D., Sportisse, B., Ahmed de Biasi, M., Debry, É., Korsakissok, I., Wu, L., Roustan, Y., Sartelet, K., Tombette, M., and Foudhil, H.: Technical Note: The air quality modelling system Polyphemus, Atmos. Chem. Phys., 7, 5479-5487, doi:10.5194/acp-7-5479-2007, 2007.

McHugh, C. A., Carruthers, D. J., Higson, H., and Dyster, S. J.: Comparison of model evaluation methodologies with application to ADMS 3 and U.S. Models, Int. J. Environ. Pollut., 16, 1-6, 2001.

Plaisance, H., Piechocki-Minguy, A., Garcia-Fouque, S., and Galloo, J. C.: Influence of meteorological factors on the $\mathrm{NO}_{2}$ measurements by passive diffusion tube, Atmos. Environ., 38, 573580, 2004.

Roustan, Y., Pausader, M., and Seigneur, C.: Estimating the effect of on-road vehicle emission controls on future air quality in Paris, France Atmos. Environ., 45, 6828-6836, 2011.

Skamarock, W. C., Klemp, J. B., Dudhia, J., Gill, D. O., Barker, D. M., Duda, M. G., Huang, X.-Y., Wang, W., and Powers, J. G.: A Description of the Advanced Research WRF Version 3. NCAR Technical Note 475+STR, http://www.mmm.ucar.edu/wrf/users/ docs/arw_v3.pdf, 2008.

Soulhac, L., Salizzoni, P., Mejean, P., Didier, D., and Rios, I.: The model SIRANE for atmospheric urban pollutant dispersion; PART II, validation of the model on a real case study, Atmos. Environ., 49, 320-357, 2012.

Venkatram, A. and Horst, T.: Approximating dispersion from a finite line source, Atmos. Environ., 40, 2401-2408, 2006.

Venkatram, A., Isakov, V., Thoma, E., and Baldauf, R.: Analysis of air quality data near roadways using a dispersion model, Atmos. Environ., 41, 9481-9497, 2007.

Venkatram, A., Isakov, V., Seila, R., and Baldauf, R.: Modeling the impacts of traffic emissions on air toxics concentrations near roadways, Atmos. Environ., 43, 3191-3199, 2009.

William, H., Teukolsky, S. A., Vetterling, W. T., and Flanner, B. P.: Chapter 4. Numerical Recipes: The Art of Scientific Computing, Cambridge University Press (ISBN-10: 0521880688, or ISBN13: 978-0521880688), 2007.

Yamartino, R.: Chapter 7B, Simulation Algorithms in Gaussian Plume Modeling, in: Air Quality Modeling - Theories, Methodologies, Computational Techniques, and Available Databases and Software, Vol III- Special Issues, edited by: Zannetti, P., Published by the EnviroComp Institute (www.envirocomp.org) and the Air Waste Manag. Assoc. (www.awma.org), 2008. 